\title{
Prevalence of atopy and range of bronchial response to methacholine in 7 and 11 year old schoolchildren
}

\author{
R D CLIFFORD, ${ }^{*} \dagger \mathrm{M}$ RADFORD, $\dagger$ J B HOWELL, ${ }^{*}$ AND S T HOLGATE* \\ Departments of *Medicine and + Child Health, University of Southampton
}

SUMmARY A sample of 397 from 2503 children aged 7 and 11 years, who took part in an earlier questionnaire study of respiratory symptoms in Southampton, was chosen for methacholine bronchial provocation and allergen skin testing. Results were obtained from $330(84 \%)$. A good level of repeatability was achieved for bronchial provocation testing giving a $95 \%$ confidence interval equivalent to 1.74 doubling concentrations. The main problem encountered with methacholine was its bitter taste in high concentrations. The proportion of children, in whom the dose of methacholine which produced a fall of $20 \%$ in the forced expiratory volume in one second ( $\mathrm{PD}_{20}$ methacholine) was $\leqslant 6.4 \mu \mathrm{mol}$, fell from $29.1 \%$ at 7 years to $16.5 \%$ at 11 years. The prevalence of atopy increased from $26 \%$ at 7 years to $31 \cdot 6 \%$ at 11 years. A highly significant association was found between bronchial responsiveness to methacholine and atopy, which was independent of symptoms or age group.

Tests for quantifying non-specific bronchial responsiveness have become commonplace in laboratory based research on asthma. In recent years both histamine and methacholine challenge tests have been introduced for use in community surveys in an attempt to enhance the specificity of questionnaire studies of asthma because of difficulties in the symptomatic definition of this group of diseases. A fixed dose methodology suitable for epidemiological use has recently been described and validated by Yan et al and shown to be safe, easy to perform, and highly reproducible in adults. ${ }^{12}$ The same group have recently reported the use of the method in an epidemiological study of Australian schoolchildren.

In adults Mortagy et al have described a collection of symptoms associated with a defined degree of bronchial responsiveness to histamine. ${ }^{3}$ It is likely that a significant proportion of asthmatic individuals may fail to show bronchial hyper-responsiveness on a single measurement, a phenomenon that appears to be particularly common in children. ${ }^{45}$ It is unclear how many individuals may have measurable hyper-responsiveness without symptoms as studies purporting to show this have failed to enquire about all respiratory symptoms and in particular cough, or have failed to separate the latter symptom in their analyses.

Other studies have shown an association between bronchial responsiveness and atopy and indicating a causal interaction..$^{6-9}$ The precise role of these two measurements, however, in the aetiology and symptomatic definition of asthma and other respiratory complaints remains a subject of speculation. In this study we have examined the range of bronchial responsiveness and atopy among children randomly selected from a variety of respiratory symptom groups. Moreover, we have endeavoured to optimise the precision of the methodology of Yan et al for testing non-specific bronchial responsiveness in children, ${ }^{p}$ and have measured its repeatability and comparability with another commonly used method.

\section{Subject and methods}

\section{SUBJECTS}

The questionnaire part of the study was undertaken in the summer term in 55 schools among 2981 third year first and middle school children between 6.8 and 7.8 years and 10.8 and 11.8 years respectively. The questionnaire used has been described previously. ${ }^{10}$

Children were divided into seven symptom groups according to answers given on the questionnaire (table 1). Each symptom group except group 7 referred to symptoms within 12 months from delivery of the questionnaire. Children in group 2 (cough) did not have wheeze or shortness of breath. Parents of children in group 6 (bronchial irritability) 
Table 1 Distribution of symptoms in the general population, numbers of children invited for testing, and numbers finally tested for atopy and bronchial responsiveness to methacholine

\begin{tabular}{|c|c|c|c|c|}
\hline Symptom group & $\begin{array}{l}\text { Population } \\
\text { No }(\%)^{*}\end{array}$ & $\begin{array}{l}\text { No invited } \\
\text { for testing }\end{array}$ & $\begin{array}{l}\text { No tested } \\
\text { for bronchial } \\
\text { responsiveness } \\
\text { to methacholine }\end{array}$ & $\begin{array}{l}\text { No tested } \\
\text { for atopy }\end{array}$ \\
\hline $\begin{array}{l}1 \text { None } \\
2 \text { Cough alone } \\
3 \text { Wheeze with or without cough } \\
4 \text { Shortness of breath with or without cough } \\
5 \text { Wheeze and shortness of breath } \\
\text { with or without cough } \\
6 \text { Bronchial irritability } \\
7 \text { Past wheeze/shortness of breath } \\
8 \text { Incomplete information }\end{array}$ & $\begin{array}{rr}1063 & (47 \cdot 4) \\
348 & (15 \cdot 5) \\
142 & (6 \cdot 3) \\
61 & (2 \cdot 7) \\
& \\
150 & (6 \cdot 7) \\
445 & (19 \cdot 8) \\
34 & (1 \cdot 5) \\
260 & \end{array}$ & $\begin{array}{r}109 \\
66 \\
58 \\
26 \\
\\
60 \\
68 \\
10\end{array}$ & $\begin{array}{l}80 \\
55 \\
51 \\
24\end{array}$ & $\begin{array}{r}81 \\
54 \\
51 \\
24 \\
\\
57 \\
56 \\
9\end{array}$ \\
\hline
\end{tabular}

*No of questionnaire replies classified to each symptom group also represented in parentheses as a percentage of the children on which complete information is available.

†See text for explanątion of symptom group.

had answered negatively to the cough, wheeze, and shortness of breath sections, although admitting to one or more of these symptoms in response to environmental provoking agents including cold air, fumes, smoke, and exercise. Children were only placed into group 7 (past wheeze/shortness of breath) if they did not fall into any of the current symptom groups (2-6). Symptom groups were thus mutually exclusive. Children in the wheeze and shortness of breath sections invariably also had cough and bronchial irritability as additional symptoms.

From 1 October until the end of the autumn term 1985, 20 visits were made to first schools and 20 to middle schools each providing 10 appointments for testing of atopic status and non-specific bronchial responsiveness. Schools were chosen according to the headteacher's assessment of the appropriateness of facilities comprising 27 of the 55 schools involved in the questionnaire study. One hundred children in group 1 were originally selected together with all children from groups $3,4,5$, and 7 from the participating schools. The rest of the cases were split between groups 2 and 6 to make a total of 400 with equal numbers in each of the two age groups. Children were not selected if parents had indicated a wish not to be contacted further on the appropriate portion of the questionnaire. Some children had moved school and were replaced by children in group 1 not in the original selection. Selection of children from groups 1,2 , and 6 was random. Three children, thought by the administration to still be at the school, turned out to have left when the school was visited for testing, reducing the test selection to 397.
Parents were sent an explanatory leaflet together with a consent form at least two weeks before testing was due to take place. Ethical approval was obtained from the Southampton University and Hospital's ethics subcommittee.

\section{BRONCHIAL PROVOCATION TESTING}

The methodolgy of Yan et al was chosen for its simplicity and ease of use in the field. ${ }^{1}$ Methacholine was used as the provoking agent because of its lower incidence of side effects, stability in solution, and economy. On a molar basis its potency as a bronchoconstrictor agent is reputed to be similar to that of histamine. ${ }^{11}$ The DeVilbiss No 40 hand held nebulisers were used (DeVilbiss). The mean output of the nebuliser per actuation was calculated for each unit by weighing the nebuliser before and after 100 consecutive aerosol deliveries. The procedure was carried out on five separate days to calculate the day to day repeatability in the form of a coefficient of variation. In addition, serial measurements of mean output per actuation were made by weighing before and after 10 puffs on 10 successive occasions from which could be calculated the coefficient of variation from one actuation to another. A number of nebulisers were tested and the best four chosen for delivery of the methacholine solutions in the study. The information obtained from these measurements is summarised in table 2 .

Increasing doses of methacholine were administered to subjects using one to six puffs from the four nebulisers containing varying concentrations of methacholine solution. The methodology for testing has been described in detail elsewhere. ${ }^{12}$ After an initial inhalation of normal saline subjects were 
Table 2 Aerosol output data on the four nebulisers used in the study

\begin{tabular}{|c|c|c|c|c|}
\hline & \multicolumn{4}{|c|}{ Nebulisers } \\
\hline & 1 & 2 & 3 & 4 \\
\hline Output/puff (ml $\left.\times 10^{-3}\right)$ & $3 \cdot 13$ & 2.30 & 2.07 & 1.98 \\
\hline Coefficient of variation/puff (\%) & 17 & 9 & 17 & 12 \\
\hline Coefficient of variation/day (\%) & 2 & 3 & 2 & 3 \\
\hline Required output/puff ( $\mu \mathrm{mol})$ & $0 \cdot 8$ & 0.4 & $0 \cdot 1$ & 0.025 \\
\hline Solution concentration (M) & $0 \cdot 255$ & $0 \cdot 174$ & 0.048 & 0.013 \\
\hline Solution concentration ( $\mathrm{g} \%$ ) & $5 \cdot 00$ & 3.40 & 0.947 & $0 \cdot 248$ \\
\hline
\end{tabular}

given increasing doses of methacholine from 0.025 $\mu \mathrm{mol}$ to $6.4 \mu \mathrm{mol}$. The dose given was expressed cumulatively by including previous doses. Where a history of moderate to severe asthma was given, doubling doses were used. In the remaining subjects quadrupling doses were used initially-moving to a doubling dose regime if a fall of $10 \%$ from the postsaline value occurred. The test was continued until either the highest dose had been administered or a greater than $20 \%$ drop in forced expiratory volume in one second $\left(\mathrm{FEV}_{1}\right)$ from the postsaline measurement had been recorded. Any bronchoconstriction caused by the methacholine was then reversed with inhaled salbutamol via a $750 \mathrm{ml}$ valved spacer device (Volumatic, Allen and Hanburys). The cumulative provocation dose of methacholine required to cause a $20 \%$ fall in $\mathrm{FEV}_{1}$ from postsaline baseline ( $\mathrm{PD}_{20}$ methacholine) was calculated from a log dose response curve by linear interpolation. Children were divided into two groups according to whether they showed bronchial responsiveness to $\leqslant 6.4 \mu \mathrm{mol}$ of methacholine, the top dose used. Eighteen children did not undergo bronchial provocation testing because they had an initial $\mathrm{FEV}_{1}$ of $<75 \%$ expected for height. Fourteen of these showed reversability of airways obstruction by a $>10 \%$ rise in $\mathrm{FEV}_{1}$ in response to salbutamol. A further child showed a fall in $\mathrm{FEV}_{1}$ of $>20 \%$ in response to the forced expiratory manoeuvre but reversed with salbutamol. For the purposes of analysis we included these 15 children within the group who showed bronchial responsiveness to methacholine.

The repeatability of the test was measured by testing 32 children on two separate occasions: on successive days in nearly all cases and in all cases within one week. Three children fell outside the range of the test on one or both days. Results were thus obtained on 29 children. It was also possible to retest a further 13 children using the classical method of Cockcroft $e t$ al to derive an estimate of comparability between the two challenge methods. ${ }^{13}$
SKIN TESTING

Allergen diluent and histamine controls together with three allergen extracts-house dust mite (Dermatophagoides pteronyssinus), mixed grass pollens, and cat dander (Bencard)-were used for intradermal testing. These allergens were chosen because they have previously been shown to identify $>98 \%$ of atopic children in the United Kingdom. ${ }^{14}{ }^{15}$ The skin was pricked through the forearm using a sterile 25 gauge needle without drawing blood. Any weals produced by the control solutions or allergen extracts were measured after 10 minutes and the diameters recorded. Those with diameters $\geqslant 3 \mathrm{~mm}$ were scored positive. Children were excluded if the allergen diluent control produced a weal of $\geqslant 3 \mathrm{~mm}$ or if the histamine control failed to produce a weal greater than the diluent control. Children with one or more positive result were classed as atopic.

\section{STATISTICAL ANALYSIS}

The Statistical Package for Social Sciences edition X was used for categorisation and analysis of data. ${ }^{16}$

\section{Results}

\section{RESPONSE RATES}

The 397 test appointments represented one sixth of the 2503 replies to the questionnaire but, because of the selection procedure, a higher proportion of the symptomatic children (table 1). Of these $341(86 \%)$ attended for testing with the consent of their parents. Four children refused bronchial provocation testing and seven were unable to perform the test manoeuvres. Thus $97 \%$ of children attending were successfully tested for bronchial responsiveness and comprised $83 \%$ of all children selected. Four children refused skin testing and in five further cases results were not recorded in error; results were thus obtained for 332 children $(84 \%$ of selected children, $97 \%$ of attenders). Skin test results from three children were excluded because of inappropriate control results.

Methacholine did not cause a hoarse voice or flushing as occurs with high concentrations of histamine. ${ }^{11}$ After methacholine challenge there were no cases of severe bronchoconstriction and in all children rapid reversal occurred after inhalation of salbutamol. Three children complained of dizziness thought to be related to hyperventilation. One child became briefly tearful during testing but quickly recovered and completed the test with the encouragement of her mother. The major complaint from nearly all the children reaching the top concentration of methacholine was its bitter taste. Many children required considerable encourage- 


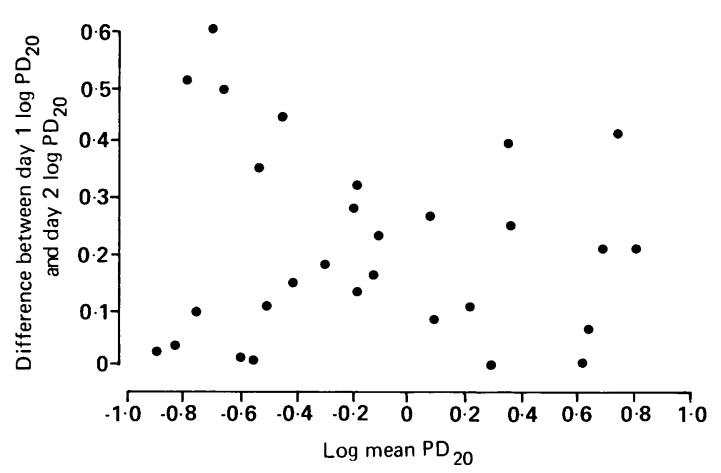

Figure Difference between two sereial $P D_{20}$ methacholine measurements plotted against mean $P D_{20}$. (Altman and Bland. ${ }^{17}$ )

ment to complete the test because of this characteristic.

\section{REPEATABILITY AND COMPARABILITY}

The difference between the two repeat measurements of $\log \mathrm{PD}_{20}$ is plotted against the mean $\log$ $\mathrm{PD}_{20}$ in the figure. It can be seen that there was no association between the size of the difference and the responsiveness of the subject, thus justifying the use of a $t$ distribution to describe the repeatability of the method. ${ }^{17}$ The standard deviation of the difference day $1 \log \mathrm{PD}_{20}$ - day $2 \log \mathrm{PD}_{20}$ was 0.256 giving a $95 \%$ confidence interval of 0.524 equivalent to 1.74 doubling concentrations or a factor of $3 \cdot 34$.

Two of the children retested using the Cockcroft method were excluded because of changes in asthma control between tests resulting in large changes in bronchial responsiveness so that data was available on 11 children. The Cockcroft method gives a result in terms of concentration of methacholine (nebul- ised over a fixed interval) producing a $20 \%$ fall in $\mathrm{FEV}_{1}\left(\mathrm{PC}_{20}\right)$. The mean difference $\log \mathrm{PD}_{20}-\log$ $\mathrm{PC}_{20}$ was 0.385 equivalent to a factor of 2.4 or 1.3 doubling concentrations. Thus multiplication of the $\mathrm{PD}_{20}$ value in $\mu \mathrm{mol}$ by 2.4 gives an approximate conversion factor for the $\mathrm{PC}_{20}$ in $\mathrm{mg} / \mathrm{dl}$ using the Cockcroft method.

ATOPY AND BRONCHIAL RESPONSE TO METHACHOLINE The proportion of children shown to have bronchial responsiveness to $\leqslant 6.4 \mu \mathrm{mol}$ of methacholine (bronchial responsiveness to methacholine) and the proportion designated as atopic based on the results of the allergen skin tests are displayed in table 3 . The estimated prevalences for the whole population have been derived from the known proportion of each symptom group within the total population (table 1) and confidence intervals calculated from the summed variances for each group.

In view of a probable relationship between symptoms and both bronchial responsiveness to methacholine and atopy, ${ }^{18}$ the Mantel-Haenszel test $^{19}$ was used to control for symptoms when examining the association between bronchial responsiveness to methacholine and atopy. We also controlled for age group in view of alterations in the prevalences of atopy and bronchial responsiveness to methacholine with age (table 3). Bronchial responsiveness to methacholine remained highly significantly related to atopy when we controlled for these two factors $(p<0 \cdot 0001)$. The same test was used to measure the significance of the negative association between age and bronchial responsiveness to methacholine controlling for symptoms and atopic status. This association was also found to be highly significant $(p=0.0028)$. Similarly the positive association between atopy and age was significant $(\mathrm{p}=0 \cdot 0052)$ when controls were made for symptoms

Table 3 Proportions of children displaying bronchial responsiveness to methacholine or with one positive skin allergen test

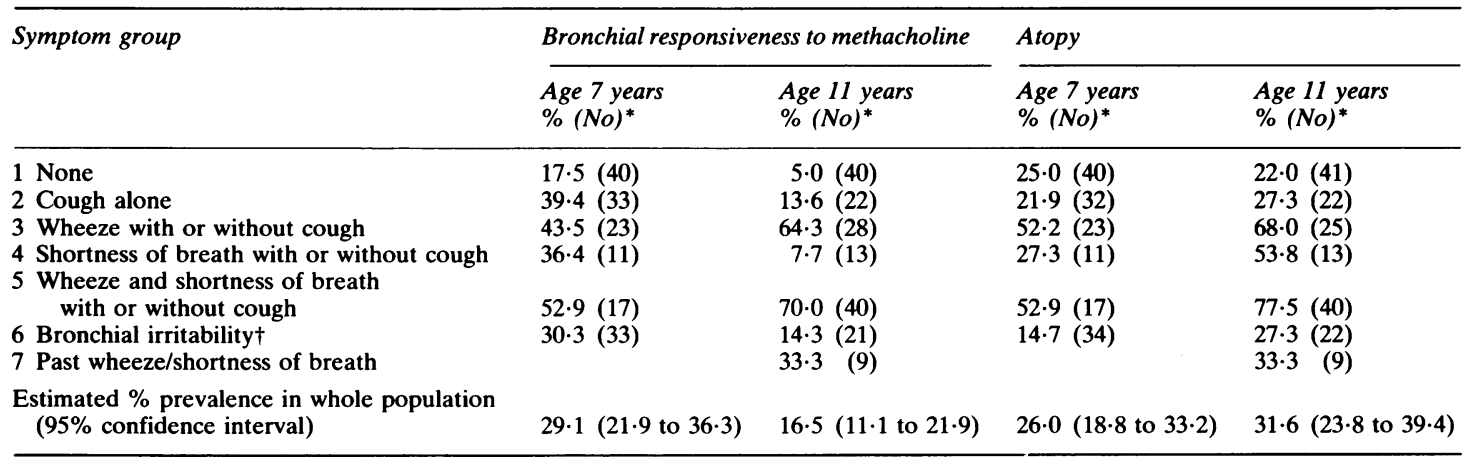

*Percentage of number of children (No) tested in that symptom group.

†See text for explanation of symptom group. 
and the presence of bronchial responsiveness to methacholine. However, there were no significant associations between sex of the child and methacholine bronchial responsiveness or the presence of atopy.

\section{Discussion}

We have confirmed the feasability of a method for bronchial provocation testing of children on a large scale in the field. While hoarse voice and flushing has been commonly reported as a problem with higher doses of histamine, methacholine is said to have no undesirable side effects. "In this study of schoolchildren we did encounter difficulties with the bitter taste of methacholine. This side effect was a potential source of difficulty and many children needed considerable encouragement to complete the six inhalations necessary for the last dose of methacholine. This exaggerated response was not predicted given the mildness of the taste to an adult and should, therefore, be taken into account in future studies involving children.

We have tested the repeatability of our methodology for bronchial provocation testing and have achieved results comparable with those obtained by Britton $e t$ al in a study of adults. ${ }^{2}$ The fact that repeated measurement of bronchial responsiveness can only produce results within a factor of three or more of each other should guard against over interpretation. For this reason as well as simplicity, we have divided children into those with $\mathrm{PD}_{20}$ values of less than or greater than $6.4 \mu \mathrm{mol}$ of methacholine, the top dose used in this study. We have thus been able to show that one group of children is more responsive to methacholine than another but not by how much. In a similar way we have classified children into atopic and non-atopic groups rather than endeavouring to produce a potentially misleading 'atopy index'. This has allowed us to test the significance of our findings using simple and reliable statistical tests designed for the analysis of categorical data.

We have used our data on the individual outputs of the nebulisers to calculate the concentrations needed for the required delivery of methacholine. Yan et al assumed a common output of $0.003 \mathrm{ml}$ for each nebuliser, although their data showed that this was not the case. 'In the present study all methacholine provocation tests were performed by a single operator using the same set of nebulisers. For epidemiological studies in which several operators are used, it would seem wise to measure the outputs of each set of nebulisers with the operators using them and to adjust the concentrations of provoking solution accordingly. Such an approach may im- prove reliability as well as comparability between studies using simlilar equipment. We recommend that a set of nebulisers is chosen with an output coefficient of variation of $<20 \%$.

Our data gives a prevalence of $29 \cdot 1 \%$ at 7 years and $16.5 \%$ at 11 years for a $\mathrm{PD}_{20}$ for methacholine of less than $6.4 \mu \mathrm{mol}$. This compares well with a recent study by Salome et al using similar methodology where $17 \cdot 8 \%$ of $8-11$ year old Australian schoolchildren had a $\mathrm{PD}_{20}$ for histamine of less than $7 \cdot 8$ mol. $^{20}$ Methacholine has been said to have a similar molar potency to histamine when used for bronchial provocation. ${ }^{11}$ The concordance between these studies suggests that this is indeed likely to be the case. This is an important consideration because of the almost interchangeable way in which the two substances have been used in different studies.

The prevalence of atopy in this study of $26 \%$ at 7 years and $31.6 \%$ at 11 years is comparable with the prevalence of $33.7 \%$ found by Godfrey and Griffiths for positivity to house dust mite or grass pollen among 303 Southampton children aged 8 to 14 years. ${ }^{21}$ The slightly higher prevalence of atopy to just two allergens recorded by Godfrey and Griffiths together with the higher age range suggests that the increase in prevalence recorded in our group between 7 and 11 years may continue to 14 years.

The differences in bronchial responsiveness to methacholine and atopy found between the two age groups reached a high level of significance but, surprisingly, occurred in opposite directions despite a strong association between atopy and bronchial responsiveness to methacholine. An age related change in bronchial responsiveness has not been previously reported. It is possible for apparently significant associations between unrelated variables to occur in epidemiological studies by chance where an undiscriminating examination has been made of any possible interactions between a large number of variables. In this study, however, only a small number of interactions were examined based upon hypothesis testing, in particular: those between atopy and bronchial responsiveness to methacholine and between each of these measurements and age sex, and three respiratory symptoms. It is unlikely that the differences in bronchial responsiveness to methacholine and atopy observed between the two ages is due to other differences between the two groups as the method of selection was random with a broad spectrum between a large number of schools. The numbers of children within each symptom group were necessarily different but we have controlled for this in our analyses.

It might be thought likely that differences in bronchial responsiveness between the two ages could be the result of differences in airway calibre 
Although bronchial responsiveness has been widely studied, there is no reported interaction with height, indeed such an interaction would invalidate a number of studies now reported in the literature in adults, children and infants. Airway resistance varies with the fourth power of diameter, although the association is more complex during turbulent flow which may occur during a forced manoeuvre. However, tests of bronchial responsiveness depend upon a standard change in airway resistance (usually resulting in a $20 \%$ fall in $\mathrm{FEV}_{1}$ ). A given percentage change in airway diameter will result in a larger percentage change in airway resistance but the association between the two will be the same for airways of different sizes providing that there are not substantial differences with respect to turbulent flow and airway closure. The latter assumption is not unjustified as the use of a $20 \%$ fall in $\mathrm{FEV}_{1}$ as our endpoint required only a minimal degree of bronchoconstriction. It is also improbable that the difference between the two ages is dose related as the variation in size between the children would be grossly outweighed by the use of doubling doses of bronchoconstrictor agent.

The high rate of atopy and the presence of bronchial hyper-responsiveness in asthmatic children and adults is well described, ${ }^{22}{ }^{23}$ and therefore our finding of a statistical association between the two phenomena is not surprising. In this study we have further shown a highly significant association between the presence of bronchial hyperresponsiveness and atopy which, in being independent of symptoms, indicates a likely interaction between the two phenomena. However, the contrast between the rise in atopy and fall in bronchial responsiveness between 7 and 11 years supports the view that bronchial hyper-responsiveness and atopy are two independently occurring phenomena which nevertheless have important interactions with each other. These age related changes contrast with the absence of a significant change in wheeze prevalence between 7 and $11^{1}$ perhaps indicating that they counteract each other.

We failed to show any association between gender and either bronchial responsiveness or atopy. In the questionnaire part of the study a highly significant association between gender and wheeze was shown among two and half thousand children. ${ }^{10}$ The difference was, however, small and the power of the study high. The smaller numbers of children tested for atopy and bronchial responsiveness mitigated against showing a similar small difference.

In this study we have shown that reliable information may be obtained from bronchial provocation testing of primary school children using simple equipment in the field. Our data indicates a de- crease in bronchial responsiveness between 7 and 11 years in contrast with an increase in atopy. Nevertheless atopy and bronchial responsiveness have a close statistical association even when controlling for the presence of respiratory symptoms including wheeze. Careful analysis of the inter-relationships between these variables is necessary to elucidate the nature of this interaction and its significance.

The authors would like to thank Mrs $L$ Jackson for performing the allergen skin tests, Mr M Mullee for his valuable help with the computing, and Dr M Campbell for helpful statistical advice.

The work was supported by a project grant from the Asthma Research Council.

\section{References}

1 Yan K, Salome C, Woolcock AJ. Rapid method for measurement of bronchial responsiveness. Thorax 1983;38:760-5.

2 Britton J, Mortagy A, Tattersfield A. Histamine challenge testing: a comparison of three methods. Thorax 1986;41:128-32.

${ }^{3}$ Mortagy AK, Howell JB, Waters WE. Respiratory symptoms and bronchial reactivity: identification of a syndrome and its relation to asthma. $\mathrm{Br} \mathrm{Med} J$ 1986;293:525-9.

4 Lee DA, Winslow NR, Speight ANP, Hey EN. Prevalence and spectrum of asthma in childhood. $\mathrm{Br}$ Med $J$ 1983;286:1256-8.

5 Sears MR, Jones DT, Holdaway MD, et al. Prevalence of bronchial reactivity to inhaled methacholine in New Zealand children. Thorax 1986;41:283-9.

${ }^{6}$ Cockcroft DW, Ruffin PE, Dolovich J, Hargreave FE. Allergen induced increase in non-allergic bronchial reactivity. Clin Allergy 1977;7:503-13.

7 Cartier A, Bandouvaki J, Ryan G, Dolovich H, Hargreave FE. Asthma and increased non-allergic bronchial responsiveness to methacholine during natural exposure to ragweed pollen. Am Rev Respir Dis (Suppl) 1980;121:61.

8 Boulet LP, Cartier A, Thomson NC, Roberts RS, Dolovich J, Hargreave FE. Asthma and increase in non-allergic bronchial responsiveness from seasonal pollen exposure. J Allergy Clin Immunol 1983;71:399-406.

9 Platts-Mills TA, Tovey ER, Mitchell EB, Mozarro H. Long term effects of living in a dust free room on patients with allergic asthma-reversal of bronchial hyperreactivity. Monogr Allergy 1983;18:153-5.

10 Clifford RD, Radford M, Howell JB, Holgate ST. Prevalence of respiratory symptoms among 7 and 11 year old schoolchildren and association with asthma. Arch Dis Child 1989;64:1118-25.

11 Woolcock AJ, Yan K, Salome C. Methods for assessing bronchial reactivity. Eur J Respir Dis 1983;(suppl 128)64: 181-94.

12 Clifford RD, Pugsley A, Radford M, Holgate ST. Symptoms, atopy, and bronchial response to methacholine in parents with asthma and their children. Arch Dis Child 1987;62:66-73.

13 Cockcroft DW, Killian DN, Mellon JJ, Hargreave FE. Bronchial reactivity to inhaled histamine: a method and clinical survey. Clin Allergy 1977;7:235-43.

${ }^{14}$ McCarthy OR. Selection of skin tests in asthma. $\mathrm{Br} J$ Dis Chest 1973;67:238-40.

15 Russel G, Jones SP. Selection of skin tests in childhood asthma. Br J Dis Chest 1976;70:104-6.

16 SPSSx users guide. 2nd ed. New York: McGraw-Hill, 1986.

17 Altman DG, Bland JM. Measurement in medicine: the analysis of method comparison studies. The Statistician 1983;32:307-17.

18 Clifford RD, Howell JB, Radford M, Holgate ST. Associations between respiratory symptoms, bronchial response to methacholine, and atopy in two age groups of schoolchildren. Arch Dis Child 1989;64:1133-9. 
19 Snecdor GW, Cochran WG. Statistical methods. 6th ed. Iowa: Iowa State University Press, 1967:255-6.

${ }^{20}$ Salome CM, Peat JK, Britton WJ, Woolcock AJ. Bronchial hyperresponsiveness in two populations of Australian schoolchildren-I. Relation to respiratory symptoms and diagnosed asthma. Clin Allergy 1987;17:271-81.

${ }^{21}$ Godfrey RC, Griffiths M. The prevalence of immediate positive skin tests to Dermatophagoides pteronyssinus and grass pollen in schoolchildren. Clin Allergy 1976;6:79-82.

22 Burney PGJ, Britton JR, Chinn S, et al. Descriptive epidemiology of bronchial reactivity in an adult population: results from a community survey. Thorax 1987;42:38-44.
${ }^{23}$ Peat JK, Britton WJ, Salome CM, Woolcock AJ. Bronchial hyperresponsiveness in two populations of Australian schoolchildren-II. Relative importance of aetiological factors. Clin Allergy 1987;17:283-90.

Correspondence and requests for reprints to Dr RD Clifford, Institute of Child Health, Royal Hospital for Sick Children, St Michael's Hill, Bristol BS2 8BJ.

Accepted 17 January 1989

See p 1194 